Original Article

\title{
Comparison of trunk and hip muscle activity during different degrees of lumbar and hip extension
}

\author{
SANG-MIN KIM ${ }^{1)}$, WON-GYU YOO ${ }^{2}{ }^{*}$ \\ 1) Department of Physical Therapy, The Graduate School, Inje University, Republic of Korea \\ 2) Department of Physical Therapy, College of Biomedical Science and Engineering, Inje University: \\ 607 Obangdong, Gimhae, Gyeongsangnamdo 621-749, Republic of Korea
}

\begin{abstract}
Purpose] This study compared the activity of trunk and hip muscles during different degrees of lumbar and hip extension. [Subjects] The study enrolled 18 participants. [Methods] Two exercises (hip and lumbar extension) and two ranges $\left(180^{\circ}\right.$ and $\left.<180^{\circ}\right)$ were studied. [Results] Differences in degree of extension affected the percentage maximal voluntary isometric contraction of the lumbar erector spinae and biceps femoris muscles, with significantly higher average values at $>180^{\circ}$ than at $180^{\circ}$ lumbar extension. No significant differences were found in gluteus maximus activity according to exercise type or range. [Conclusion] Hip extension may be more effective and safer for lumbar rehabilitation than lumbar extension.

Key words: EMG, Hip extension, Lumbar extension
\end{abstract}

(This article was submitted Apr. 15, 2015, and was accepted May 25, 2015)

\section{INTRODUCTION}

As an intervention, isolated lumbar exercises significantly reduce pain, and there is a relationship between improvement in lumbar extension strength and disability ${ }^{1}$. Therefore, lumbar and hip extension exercises have been recommended for programs aimed at prevention and rehabilitation of low back pain $(\mathrm{LBP})^{2,3)}$. One study investigated lumbar spine loading and muscle activity during six extensor exercises using electromyography (EMG) and the Isotrak position-tracking system $^{4}$. Trunk extension involving lumbar hyperextension resulted in greater shear force on the lumbar joints and was considered unwise for rehabilitation. Lumbar extension activates the thoracic and lumbar muscles, whereas hip extension activates the lumbar muscles ${ }^{5}$. However, lumbar hyperextension frequently occurs during overhead work and during squats while weightlifting, with athletes significantly hyperextending the lumbar spine at heavier weights 6,7 ). When patients with LBP performed exercises that included lumbar hyperextension, there was a significant decrease in LBP and improved flexibility of the spine ${ }^{7}$. A few studies have objectively quantified the changes in muscle activity, comparing prone lumbar hyperextension with hip hyperextension. Therefore, this study compared trunk and hip muscles activity during lumbar and hip extension at different degrees of extension.

*Corresponding author. Won-gyu Yoo (E-mail: won7y@inje. ac.kr)

C2015 The Society of Physical Therapy Science. Published by IPEC Inc. This is an open-access article distributed under the terms of the Creative Commons Attribution Non-Commercial No Derivatives (by-ncnd) License $<$ http://creativecommons.org/licenses/by-nc-nd/3.0/>.

\section{SUBJECTS AND METHODS}

Eighteen healthy males $(23.3 \pm 1.8$ years, weight 74.2 $\pm 7.2 \mathrm{~kg}$, height $177.4 \pm 5.3 \mathrm{~cm}$ ) participated in the study. All participants gave written informed consent according to the protocol approved by the Inje University Faculty of Health Science Human Ethics Committee. The surface EMG data were collected using a Trigno wireless system (Delsys, Boston, MA). Three surface electrodes were attached over the lumbar erector spinae (LES) at the third lumbar vertebra, gluteus maximus (GM), and biceps femoris (BF). The subjects performed four exercises: lumbar extension (LE); lumbar extension at $>180^{\circ}$ (LE over 180); hip extension (HE); and hip extension at $>180^{\circ}$ (HE over 180). For LE, the subjects performed the Sorenson test at the end of a table (isometric). Then, the subjects were placed prone on the table with the anterior-superior iliac spine (ASIS) at the edge of table. Their ankles and knees were fixed using a non-elastic belt, and a bar indicator was used to maintain the exact posture. For LE over 180, the subjects were asked to maintain maximum comfortable lumbar extension on the floor, with their ankles and knees fastened by a non-elastic belt. For HE, which was the reverse of the LE condition, the subject were asked to put their upper body on the table with the ASIS at the edge of table and to lift both legs with the knee at $180^{\circ}$ extension. For the $>180^{\circ} \mathrm{HE}$, the subjects were asked to maintain maximum hip extension while lying on the floor with a non-elastic belt placed around the scapular spines. Each subject performed two trials of each exercise at maximal voluntary isometric contraction (MVIC) against manual resistance, in accordance with previous reports ${ }^{7)}$. The normalized values for LES, GM, and BF activity are presented as the percentage MVIC (\%MVIC). Differences in the \%MVIC of the muscles were evaluated using SPSS 
ver. 18.0 (SPSS, Chicago, IL, USA). Two-way repeatedmeasures analysis of variance (ANOVA) was performed to evaluate differences in the \%MVIC, with type and degree of extension as factors. For pairwise multiple comparison, the Bonferroni correction was performed to identify differences. The level of significance was set at $p<0.05$.

\section{RESULTS}

The average \%MVIC for the LES and BF was significantly $(\mathrm{p}<0.05)$ higher during lumbar extension at $>180^{\circ}$ than at $180^{\circ}$. There were no significant differences in GM activity according to range and no significant differences in LES, GM, and BF muscle activity during LE vs. HE ( $p$ > 0.05) (Table 1).

\section{DISCUSSION}

About $60 \%$ of the weight of the human body is in the head, upper trunk, and upper limbs, and about $40 \%$ is in the lower trunk and limbs ${ }^{8)}$. Consequently, HE and LE involve substantially different loads and degrees of muscle effort. The distribution of human weight imposes a greater load during lumbar extension than during hip extension exercises, exerting greater anteroposterior shear forces and requiring greater effort. Yet, despite the greater load during the lumbar extension trials, the activity of the LES, GM, and BF muscles did not differ significantly between the LE and HE conditions, although on average, the activity of all three muscles was higher during HE. Therefore, we postulate that $\mathrm{HE}$ is a more effective exercise for strengthening and rehabilitating the LES, GM, and BF. Our results showed that significantly more LES and BF muscle fibers were recruited in the $>180^{\circ}$ condition. Although lumbar hyperextension exercises have been shown to involve excessive compression and shear forces that may lead to LBP, those studies also showed that the anteroposterior shear forces were significantly higher at $180^{\circ}$ than at $>180^{\circ} \mathrm{LE}^{4,9)}$. We think that greater co-contraction of the LES, GM, and BF may reduce excessive compression and shear forces, supporting the previous studies ${ }^{4,9)}$. One study reported that cervical hyperextension lead to significantly increased range of motion and reduced
Table 1. Comparison of muscles activities in 4 exercises

\begin{tabular}{ccccc}
\hline & \multicolumn{4}{c}{$\%$ MVC (Mean \pm SD) } \\
\cline { 2 - 5 } Muscle & \multicolumn{2}{c}{ Range in $180^{\circ}$} & \multicolumn{2}{c}{ Range over $180^{\circ}$} \\
\cline { 2 - 5 } & $\begin{array}{c}\text { Lumbar } \\
\text { extension }\end{array}$ & $\begin{array}{c}\text { Hip } \\
\text { extension }\end{array}$ & $\begin{array}{c}\text { Lumbar } \\
\text { extension }\end{array}$ & $\begin{array}{c}\text { Hip } \\
\text { xtension }\end{array}$ \\
\hline LES & $66.8 \pm 11.5$ & $77.6 \pm 13.2$ & $80.0 \pm 10.2^{*}$ & $79.2 \pm 13.1$ \\
GM & $53.5 \pm 28.9$ & $62.3 \pm 27.1$ & $71.4 \pm 35.5$ & $56.5 \pm 20.2$ \\
BF & $85.9 \pm 53.8$ & $109.5 \pm 78.6$ & $123.7 \pm 81.2^{*}$ & $104.3 \pm 75.1$ \\
\hline
\end{tabular}

$* \mathrm{p}<0.05$

pain $^{7}$. Although spine range of motion is a major factor in LBP, our results suggest that lumbar exercises at $>180^{\circ}$ may prevent injury during lumbar hyperextension.

\section{REFERENCES}

1) Smith D, Bissell G, Bruce-Low S, et al.: The effect of lumbar extension training with and without pelvic stabilization on lumbar strength and low back pain. J Back Musculoskeletal Rehabil, 2011, 24: 241-249. [Medline]

2) Yoo WG: Comparison of the isolated contraction ratios of the hip extensors and erector spinae muscles of the lumbar region and thoracic muscles during different back extension exercises. J Phys Ther Sci, 2015, 27: 315-316. [Medline] [CrossRef]

3) Searle A, Spink M, Ho A, et al.: Exercise interventions for the treatment of chronic low back pain: a systematic review and meta-analysis of randomised controlled trials. Clin Rehabil, 2015, [Epub ahead of print]. [Medline] [CrossRef]

4) Callaghan JP, Gunning JL, McGill SM: The relationship between lumbar spine load and muscle activity during extensor exercises. Phys Ther, 1998, 78: 8-18. [Medline]

5) De Ridder EM, Van Oosterwijck JO, Vleeming A, et al.: Posterior muscle chain activity during various extension exercises: an observational study. BMC Musculoskelet Disord, 2013, 14: 204. [Medline] [CrossRef]

6) Walsh JC, Quinlan JF, Stapleton R, et al.: Three-dimensional motion analysis of the lumbar spine during "free squat" weight lift training. Am J Sports Med, 2007, 35: 927-932. [Medline] [CrossRef]

7) Manniche $C$, Asmussen $K$, Lauritsen $B$, et al.: Intensive dynamic back exercises with or without hyperextension in chronic back pain after surgery for lumbar disc protrusion. A clinical trial. Spine, 1993, 18: 560-567. [Medline] [CrossRef]

8) Drillis R, Contini R, Bluestein M: Body segment parameters: a survey of measurement techniques. Artif Limbs, 1964, 8: 44-66. [Medline]

9) Kendall FP, McCreary EK, Provance PG, et al.: Muscles: Testing and Function with Posture and Pain, 5th ed. Baltimore: Lippincott Williams \& Wilkins, 2005. 